\title{
Review: new generation antipsychotic drugs may reduce relapse rates more effectively than conventional antipsychotic drugs in people with schizophrenia
}

Leucht S, Barnes TRE, Kissling W, et al. Relapse prevention in schizophrenia with new generation antipsychotics: a systematic review and exploratory meta-analysis of randomized, controlled trials. Am J Psychiatry 2003;160:1209-22.

What is the potential of new generation antipsychotic drugs to improve adherence and decrease relapse rates in people with schizophrenia?

METHODS

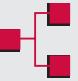

Design: Systematic review with meta-analysis

Data sources: Medline (1996-April 2001), Current Contents (January 2001-May 2001) and the Cochrane Schizophrenia Group's trial register (to July 2002); hand searches of bibliographies and contact with pharmaceutical companies. Study selection and analysis: Randomised controlled trials, reporting on relapse rates and of $\geqslant 6$ months' duration, comparing new generation antipsychotic drugs with placebo or conventional antipsychotics in people with schizophrenia or schizophrenia-like psychoses. Data were extracted on relapse, dropout resulting from adverse effects and overall treatment failure (defined as the number of people who relapsed, dropped out for any reason, or suffered an adverse event).

Fine failure.

\section{MAIN RESULTS}

Seventeen studies of 7 different new generation antipsychotic drugs met inclusion criteria (3015 participants). There was considerable heterogeneity among studies, particularly in study design, clinical characteristics of the participants, and criteria used to assess relapse and adherence. This reduces the reliability of the meta-analysis. Because there were few trials for individual drugs, the effects of new generation antipsychotic drugs as a group were analysed. The new generation antipsychotics significantly reduced relapse rates and risk of overall treatment failure when compared with both placebo and

For correspondence: Dr Leucht, Klinik und Poliklinik für Psychiatrie und Psychotherapie der Technischen Universitüt München, Klinikum rechts der Isar, Ismaningerstr. 22, 81675 Munich, Germany; Stefan.Leucht@Lrz.tu-muenchen.de Sources of funding: a grant from the Network of Competence on Schizophrenia of the German Ministry of Education and Research and a grant to the Zucker Hillside Hospital Intervention Research Center for Schizophrenia, Glen Oaks, NY, USA. conventional antipsychotics. There was no significant difference in dropout rates due to adverse events between groups (see table).

\section{CONCLUSIONS}

As a group, new generation antipsychotic drugs were more effective in preventing relapse and overall treatment failure, than both placebo and conventional drugs.

\section{Commentary}

$\mathrm{T}$ his review by Leucht et al provides important information on the efficacy of second generation "atypical" antipsychotic drugs compared with either placebo or conventional agents. It complements a large number of randomised controlled trials (RCTs) and systematic reviews that consider short term efficacy ${ }^{\top}$ and goes some way to address questions about the efficacy of atypicals for the prevention of relapse.

In 6 placebo and 11 conventional antipsychotic controlled RCTs, atypical antipsychotics reduced relapse compared with both placebo and conventional drugs. Furthermore, the risk of dropout due to adverse events was similar to that of placebo and showed a small, if nonsignificant, advantage over conventional compounds. The studies together involve the randomisation of more than 3000 people from a wide variety of clinical settings and are likely to be generalisable to most clinicians' clinical practice. If the results stand the test of time, then atypicals will likely be regarded as the drug of first choice for the prevention of relapse in schizophrenia.

The authors state however that the advantages of atypical over conventional drugs are probably modest (NNT 13, 95\% Cl 8 to 25 for relapse) and they also highlight the known problems associated with the dose of conventional drugs. RCTs using doses of conventional drugs greater than $12 \mathrm{mg}$ of haloperidol tend to increase the advantages of atypicals for acute symptoms. ${ }^{2}$ It remains an important question whether the dose of conventional drugs influences the study effect size in studies which attempt to prevent relapse.

Andrew Mclntosh MPhil, MRCPsych

Clinical Research Fellow, Royal Edinburgh Hospital, Edinburgh, UK Stephen Lawrie MD(Hons), MRCPsych Senior Clinical Research Fellow, Royal Edinburgh Hospital, Edinburgh, UK 1 Lawrie S, Mclntosh A, Nadeem Z. Schizophrenia. Clin Evid 2002;8:1019-49.

2 Geddes J, Freemantle N, Harrison P, et al. Atypical antipsychotics in the treatment of schizophrenia: systematic overview and meta-regression analysis. BMJ 2000;321:1371-6.

Table 1 Results of new generation antipsychotic drugs compared with placebo and conventional antipsychotic drugs

\begin{tabular}{|c|c|c|c|c|c|c|}
\hline & \multicolumn{3}{|c|}{ Compared with placebo } & \multicolumn{3}{|c|}{ Compared with conventional antipsychotic drugs } \\
\hline & $\begin{array}{l}\text { New generation } \\
\text { antipsychotic drugs } \\
(n=653)\end{array}$ & $\begin{array}{l}\text { Placebo } \\
(n=330)\end{array}$ & $\begin{array}{l}\text { Relative risk }(95 \% \mathrm{Cl}) \\
\text { for new generation } \\
\text { antipsychotic drugs } \mathrm{v} \\
\text { placebo; NNT }(95 \% \mathrm{Cl})\end{array}$ & $\begin{array}{l}\text { New generation } \\
\text { antipsychotic } \\
\text { drugs, } \mathbf{n}(\%)\end{array}$ & $\begin{array}{l}\text { Conventional } \\
\text { antipsychotic } \\
\text { drugs, } \mathbf{n}(\%)\end{array}$ & $\begin{array}{l}\text { Relative risk }(95 \% \mathrm{Cl}) \text { for new } \\
\text { generation antipsychotic drugs } \\
\text { v conventional antipsychotic } \\
\text { drugs; NNT }(95 \% \mathrm{CI})\end{array}$ \\
\hline Relapse rates & $104(16 \%)$ & $109(33 \%)$ & $\begin{array}{l}\text { RR } 0.35(0.19 \text { to } 0.62) \\
\text { NNT } 5 \text { ( } 3 \text { to } 13)\end{array}$ & $161 / 1096(15 \%)$ & $142 / 614(23 \%)$ & $\begin{array}{l}\text { RR } 0.65(0.53 \text { to } 0.81) \\
\text { NNT }=13(8 \text { to } 25)\end{array}$ \\
\hline $\begin{array}{l}\text { Overall treatment } \\
\text { failures }\end{array}$ & $279(43 \%)$ & $237(72 \%)$ & $\begin{array}{l}\text { RR } 0.62(0.46 \text { to } 0.83) \\
\text { NNT } 3(3 \text { to } 4)\end{array}$ & $\begin{array}{l}646 / 1314 \\
(49 \%)\end{array}$ & $440 / 669(66 \%)$ & $\begin{array}{l}\text { RR } 0.82(0.76 \text { to } 0.89) \\
\text { NNT }=10(6 \text { to } 33)\end{array}$ \\
\hline Drop out rates & $50(8 \%)$ & $34(10 \%)$ & RR $0.68(0.21$ to 2.15$)$ & $50(8 \%)$ & $34(10 \%)$ & $\operatorname{RR} 0.89(0.68$ to 1.16$)$ \\
\hline
\end{tabular}

